\title{
Research on the Effect of Price Character on Price Overall Perception
}

\author{
Chang Xue \\ Shandong University of Finance \& Economics \\ Shungeng Road No. 40 \\ Jinan, Shandong Province, China \\ +86-531-82911123, changxue@sdufe.edu.cn
}

\begin{abstract}
Price is not mere signal of fair exchange. At the sametime, customer's act is not brief either. Price has been a crosssubjected research domain. Customer buying activity is controlled by three price perception factors that include price cheapness, price fairness and price variety. Empirical results show that price cheapness, price fairness and price variety is not only influences customer price overall perception, but also direct positively impacts it. This research fruit gives theoretical research and practitioner some guidance: qualitative research of customer price factors must up to quantitative measurement and administrative level.
\end{abstract}

Key words: price cheapness; price fairness; price variety; price perception

\section{Introduction}

Professionals have done lots of efforts so as to investigate the links between price activity and price. Especially, foreign researchers have done relevant research that emphasis on customer price activity. However, basic theory on consumer price behavior debate in particular. Customer perception on price, quality and value is considered playing decisive impact on purchasing behavior and selecting product. In the past ten years, marketing research has been focusing on these concepts and their relations, because they have an important role in the fierce competition market of current condition ${ }^{[1]}$. Although literatures do certain work in this field, figuring out the difference between these concepts ${ }^{[2]}$ and improving measurement procedures, the results still have some discussion, especially there is further research on price character and its impact in price overall perception. This paper will investigate this area.

\section{Review Literature and Figure out Problem}

\section{A. Price cheapness and consumer price evaluation}

Price always is used for demonstrating whether or not customer will acquire the various utility from the products and how to pay for the product, which expresses customer's willingness, for example, he or she will devote the maximum price so as to acquire the attribute of the product. Consumer surplus ${ }^{[3]}$ is the balance between customer's willingness to pay (the maximum price of he or she will sacrifice) and he or she's authentic payment (sellers charge price). Everything is fair.
Customer will not purchase product if its price is much more expensive than maximum price, from another point of view, there is a positive or zero consumer surplus level. Considering the utility that customer acquire from product is various, their measurement on price is not objective, which depends on the demand of customers.

Marshall defines consumer surplus is the $\mathrm{DP}^{\prime} \mathrm{E}$ domain by demand curve. Customer surplus evaluates the extra utility which customer acquiring from one product surpasses their sacrifice to pay. Hence:

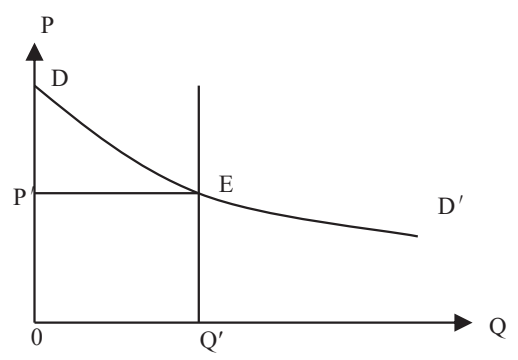

Fig. 1 Consumer surplus

H1: Price cheapness directly impacts consumer price overall perception.

Demand is the numerical sign that customer needs at a given price. That is to say, if the other situation is uncontrolled, if the price is higher, the demand less; to the contrary, if the price is lower, the demand is more. Demand law is the obvious practical relationship between price and demand. Hence:

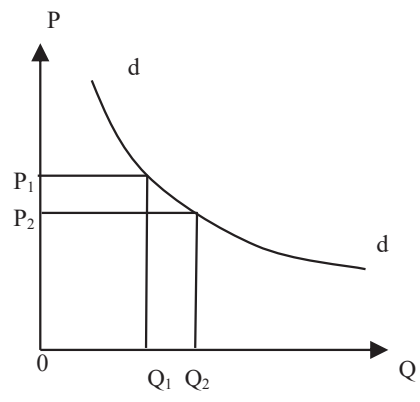

Fig. 2 Demand curve 
H2: Price cheapness direct positively impacts consumer price overall perception.

\section{B. Price fairness and consumer price evaluation}

Fairness theory analyzes the exchange between input and output ${ }^{[4]}$. Output means the perceptive outcome when participating exchange. Similarly, input means the contribution on one side of exchange. Adding together, input and output can express "fair exchange". When the participant fells their input and output is the same with their involvement degree, the transaction will occur. At the same time, when the participant fells their input and output is unequal, the transaction is considered "unfair".

Fairness theory sets up the external consideration on both sides of exchange, rather only based on the outcome of consumers ${ }^{[5]}$. Under fairness framework, the contrast between the perceived value of consumers and the perceived value of providers from certain transaction is deemed to one origin. More exactly, it is a source of transaction value. In reality, the evaluation on input and output in the relationship between buyer and seller, fairness perception impacts consumer's evaluation on actual payment, which is the perception on transaction value. The ratio between input and output is defined as "expected" foundation of reference price, that is to say, one price is considered fair or rational ${ }^{[6]}$.

This kind of expectation is the influence which is fair reference price towards real price judgment, and predicts the process of price perception increases another price dimension: price fairness. The fairness of price can be defined that comparing the obtained value of the suppliers from transaction relation, the judgment on real price whether or not is fair. Hence:

H3: Price fairness directly impacts consumer price overall perception.

Price judgment is the function of value perception character. Prospect theory gets lots of evidence from marketing practice, especially in price management field ${ }^{[7]}$. This theory provides behavior foundation on evaluating gain and loss. Consumer defines their loss and gain at reference point. The asymmetric relations among gain, loss and value in prospect theory express in S-shaped value function as Figure 3.

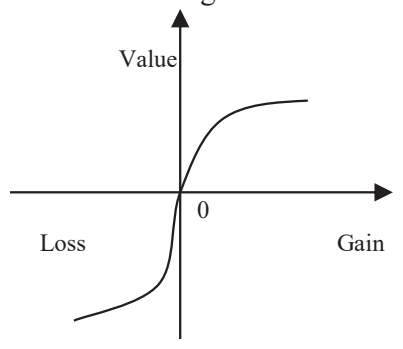

Fig. 3 Value function
One important hypothesis in prospect theory is that when evaluating the different deviation of a reference value, the negative deviation has much more influence than the positive. Namely, in the light of prospect theory ${ }^{[8]}$, consumers show strong annoyance on loss, that is "lost is much more important". When customer sense the value function upward or downward along with the middle of S-curve, they acquire less sensitive consciousness on price variety, generally speaking, price influences customer value evaluation relative little. However, when customer's feeling emphasis on the middle of S-curve, the consciousness of price fairness will become much higher. The loss perception is stronger than the gain perception, which price impacts consumer value extremely prominent. The increase of gain near reference point will sustain the sensitivity on price fairness and upgrade consumer's perception value. Hence:

H4: Price fairness direct positively impacts consumer price overall perception.

\section{Price variety and consumer price evaluation}

No matter the difference of consumers (demography variable, behavior character, profit demand, and etc), their demand might impact on their willingness to pay. Price discrepancy is considered the practice of price optimization, and price evaluation process depends on the judgment of price level. Indeed, price discrepancy is deemed to the judgment on price level. According to the demand character of different consumers, the different pricing tactics on the same product or service of manufactures lead to price variety. Hence:

H5: Price variety directly impacts consumer price overall perception.

In the light of investigating the effect of mental accounting on customer's activity, Thaler discovers "value function" with prospect theory. Fig. 3 illustrates that S-shape curve is value function. When next to reference point ( 0 in axis), customer will be much more conscious. Comparing with price fairness evaluation, there is commonness and difference on price variety evaluation. When customer discovers the value function downward or upward along with the middle of S-curve, they acquire less conscious on price variety, in general, the feeling of price variety become less conscious. In the mean-time, the influence of price on customer feeling will be reduced. This consumer feature gives theoretical support to manufacturer's differentiated pricing. Hence:

H6: Price variety direct positively impacts consumer price overall perception.

\section{Research Data and Method}

June 2018, 300 questionnaires were allocated, and 278 were call back, 265 were useful for this research.

This research adopts Likert Seven Points Scale, Table 1 shows: 
TABLE I

QUESTIONNAIRE ISSUE

\begin{tabular}{|c|c|l|}
\hline Number & \multicolumn{2}{|c|}{ Survey item } \\
\hline \multirow{3}{*}{$\begin{array}{c}\text { Price } \\
\text { cheapness }\end{array}$} & V1 & Q1 My mobile phone operator provides service at low price. \\
\cline { 2 - 4 } & V2 & Q2 My mobile phone operator provides cheap price option. \\
\cline { 2 - 4 } & V3 & Q3 My mobile phone operator provides "special” nice service. \\
\hline \multirow{3}{*}{$\begin{array}{c}\text { Price } \\
\text { fairness }\end{array}$} & V4 & Q4 My mobile phone operator provides cheap price. \\
\cline { 2 - 4 } & V5 & Q5 My mobile phone operator provides my satisfying price. \\
\cline { 2 - 4 } & V6 & Q6 My mobile phone operator provides lower price when the clients raise. \\
\hline \multirow{3}{*}{$\begin{array}{c}\text { Price } \\
\text { variety }\end{array}$} & V7 & Q7 My mobile phone operator provides kinds of service price option. \\
\cline { 2 - 4 } & V8 & Q8 My mobile phone operator permits price choice. \\
\cline { 2 - 4 } & V9 & Q9 My mobile phone operator provides same service but charges various price. \\
\hline
\end{tabular}

Using statistical software SPSS 24.0, this research calculates 9 mean and standard deviation of the measuring indexes and its numerical conclusions are as below:

TABLE II

MEAN ANd StANDARd DEVIATION

\begin{tabular}{|c|c|c|c|}
\hline Variable & Measure & Mean & S.D. \\
\hline Price cheapness measure 1 & $\mathrm{Q}_{1}$ & 4.43 & 1.03 \\
\hline Price cheapness measure 2 & $\mathrm{Q}_{2}$ & 4.42 & 1.04 \\
\hline Price cheapness measure 3 & $\mathrm{Q}_{3}$ & 4.4 & 1.03 \\
\hline Price fairness measure 1 & $\mathrm{Q}_{4}$ & 4.53 & 1.07 \\
\hline Price fairness measure 2 & $\mathrm{Q}_{5}$ & 4.52 & 1.07 \\
\hline Price fairness measure 3 & $\mathrm{Q}_{6}$ & 4.54 & 1.06 \\
\hline Price variety measure 1 & $\mathrm{Q}_{7}$ & 4.75 & 1.01 \\
\hline Price variety measure 1 & $\mathrm{Q}_{8}$ & 4.81 & 1.01 \\
\hline Price variety measure 1 & $\mathrm{Q}_{9}$ & 4.75 & 1.04 \\
\hline
\end{tabular}

Adopting corrected item-total correlation (CITC) to purify the measuring items in questionnaire.

TABLE III

CITC ANALYSIS OF VARIABLES

\begin{tabular}{|c|c|c|c|c|}
\hline Variable & Number & $\begin{array}{c}\text { Question } \\
\text { item }\end{array}$ & CITC & $\begin{array}{c}\text { Cronbach's } \\
\text { Alpha }\end{array}$ \\
\hline $\begin{array}{c}\text { Price } \\
\text { cheapness } \\
\text { evaluation }\end{array}$ & 3 & $\begin{array}{l}\mathrm{Q}_{1} \\
\mathrm{Q}_{2} \\
\mathrm{Q}_{3}\end{array}$ & $\begin{array}{l}0.972 \\
0.969 \\
0.966\end{array}$ & 0.986 \\
\hline $\begin{array}{c}\text { Price } \\
\text { fairness } \\
\text { evaluation }\end{array}$ & 3 & $\begin{array}{l}\mathrm{Q}_{4} \\
\mathrm{Q}_{5} \\
\mathrm{Q}_{6} \\
\end{array}$ & $\begin{array}{l}0.964 \\
0.955 \\
0.954 \\
\end{array}$ & 0.981 \\
\hline $\begin{array}{c}\text { Price } \\
\text { variety } \\
\text { evaluation }\end{array}$ & 3 & $\begin{array}{l}\mathrm{Q}_{7} \\
\mathrm{Q}_{8} \\
\mathrm{Q}_{9}\end{array}$ & $\begin{array}{l}0.855 \\
0.882 \\
0.855\end{array}$ & 0.934 \\
\hline
\end{tabular}

As a general rule, if the coefficient of CITC is less than 0.5, and if deletes it can improve the coefficient of $\alpha$, it must be deleted unless there is special important reasons. The coefficient of CITC in this research is more than 0.5 , and its value are between 0.855 and 0.982 . Data shows, each question item has better consistency under three dimensions of variable.

Before factor analysis with the research data, KMO and Bartlett Chi-square test are necessary.

$$
\text { TABLE IV }
$$

SAMPle KMO AND BARTLETt ChI-Square Test

\begin{tabular}{|c|c|l|}
\hline \multicolumn{2}{|c|}{ KMO test on sample adequacy } & 0.776 \\
\hline \multirow{2}{*}{$\begin{array}{c}\text { Bartlett test on sample } \\
\text { distribution }\end{array}$} & Chi-square test & 5322.916 \\
\cline { 2 - 3 } & Degree of & 36 \\
\cline { 2 - 3 } & Significance & 0.000 \\
\hline
\end{tabular}

Scree plot is derived from selecting maximum variance in rotating factor by using principal component analysis in extracting factor.

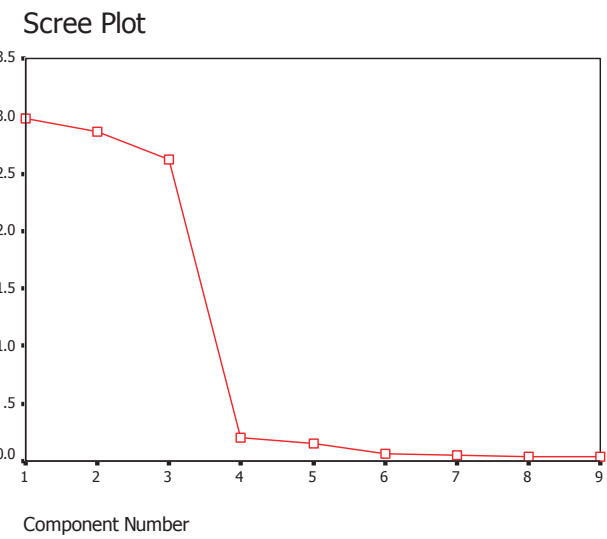

Fig. 4 Scree plot of factor analysis

The number of factor is the abscissa, and latent root is coordinate. The latent root of first factor is relative high, which 
explains the greatest demonstration in illustrating variable. Before the third latent root, the value is much more, which gives little explanation on variable. Hence, it is right to extract three factors; and from the table of explained variance, the number of latent root which is more than 1 is 3 . So, there is important to choose 3 factors respectively: factor 2 is customer price fairness measure factor (PFP), factor 3 is customer price variety perception factor (PVP).

According to correlation coefficient matrix, adopts principal component analysis extracting factors and accepts the value of latent root which is more than 1 .

That is the problem-solving method, which explains that the common degree data of all the variables. Most of the data $(\geq 80 \%)$ in each variable is illustrated by factors; in general, the data of variable is relevant less. Therefore, the utility of this factor extracting is satisfactory.

Data analyzes by SPSS 24.0, and chooses regression in estimate factor score coefficient, and illustrates them in the factor score coefficient analysis table.
TABLE V

FACTOR SCORE COEFFICIENT ANALYSIS

\begin{tabular}{|c|c|c|c|}
\hline & \multicolumn{3}{|c|}{ Factor } \\
\cline { 2 - 4 } & $1(\mathrm{PCP})$ & $2(\mathrm{PFP})$ & $3(\mathrm{PVP})$ \\
\hline Price cheapness & 0.338 & -0.002 & 0.001 \\
\hline Price cheapness & 0.338 & 0.004 & 0.006 \\
\hline Price cheapness & 0.338 & 0.003 & 0.009 \\
\hline Price fairness evaluation & 0.005 & 0.341 & -0.003 \\
\hline Price fairness evaluation & 0.001 & 0.339 & -0.007 \\
\hline Price fairness evaluation & -0.001 & 0.339 & 0.000 \\
\hline Price variety evaluation & 0.011 & -0.006 & 0.353 \\
\hline Price variety evaluation & 0.004 & -0.004 & 0.358 \\
\hline Price variety evaluation & 0.002 & 0.000 & 0.353 \\
\hline
\end{tabular}

According to the above table can get factor score function:

$\mathrm{PCP}=0.338 \mathrm{PCE}_{1}+0.338 \mathrm{PCE}_{2}+0.338 \mathrm{PCE}_{3}+0.005 \mathrm{PFE}_{1}+0.001 \mathrm{PFE}_{2}-0.001 \mathrm{PFE}_{3}+0.011+0.004 \mathrm{PVE}_{2}+0.002 \mathrm{PVE}_{3}$

$\mathrm{PFP}=-0.002 \mathrm{PCE}_{1}+0.004 \mathrm{PCE}_{2}+0.003 \mathrm{PCE}_{3}+0.341 \mathrm{PFE}_{1}+0.339 \mathrm{PFE}_{2}+0.339 \mathrm{PFE}_{3}-0.006 \mathrm{PVE}_{1}-0.004 \mathrm{PVE}_{2}$

$\mathrm{PVP}=0.001 \mathrm{PCE}_{1}+0.006 \mathrm{PCE}_{2}+0.009 \mathrm{PCE}_{3}-0.003 \mathrm{PFE}_{1}-0.007 \mathrm{PFE}_{2}+0.353 \mathrm{PVE}_{1}+0.358 \mathrm{PVE}_{2}+0.353 \mathrm{PVE}_{3}$

When calculates the value of three factor score variable, price cheapness, price fairness and price variety has higher weight in each independent factor, and has lower weight in the other factor, which is correspondent in reality. The feature of three factor score equation manifests that rice cheapness, price fairness and price variety have positive influence on consumer price overall perception. Hence, these hypotheses come true:

H1: Price cheapness directly impacts consumer price overall perception.

$\mathrm{H} 2$ : Price cheapness direct positively influences consumer price overall perception.

H3: Price fairness directly impacts consumer price overall perception.

H4: Price fairness direct positively impacts consumer price overall perception.

H5: Price variety directly impacts consumer price overall perception.

H6: Price variety direct positively impacts consumer price overall perception.

\section{Conclusions}

This paper builds dialectic relation among consumer price overall perception character that is made up cheapness, fairness and variety based on consumer surplus theory, prospect theory and mental accounting theory. Consumer purchasing decision is not only determined by price cheapness, but is also moderated by price fairness and price variety in the perception of transaction. This paper unveils the impact of price character towards consumer price overall perception and gives the theoretical direction to marketing management.

\section{Acknowledgement}

Thanks to jy201823 founded by Shandong University of Finance and Economics.

\section{References}

[1] Woodruff, R. B., Customer Value: the Next Source for Competitive Advantage, Journal of the Academy of Marketing Science, 25(2), 1997, pp.139-153.

[2] Zeithaml, V., Consumers' Perception of Price, Quality, and Value: a Means-End Model and Synthesis of Evidence, Journal of Marketing, Vol.52 No.3, 1988, pp.2-22.

[3] Vives, X., Small Income Effects: a Marshallian Theory of Consumer Surplus and Downward Sloping Demand, The Review of Economic Studies, 54(1), 1987, pp.87-103.

[4] Walster, E., E. Berscheid, and G. W. Walster, New Directions in Equity Research, Journal of Personality and Social Psychology, 25, 1973, pp.151-176.

[5] Oliver, Richard L. and John E. Swan, Consumer Perceptions of Interpersonal Equity and Satisfaction in Transactions: a Field Survey Approach, Journal of Marketing, 53(April), 1989, pp.2135 .

[6] Thaler, Richard, Mental Accounting and Consumer Choice, Marketing Science, 4 (Summer), 1985, pp.199-214.

[7] Monroe, Kent B., Pricing: Making Profitable Decisions, New York: McGraw-Hill, 1990.

[8] Kahneman, Daniel and Amos Tversky, Prospect Theory: an Analysis of Decision under Risk, Econometrica, 47(March), 1979, pp.263-291. 